\title{
O Psicólogo e o atendimento a pacientes com ideação ou tentativa de suicídio
}

\section{The psychologist and the care of patients with suicidal ideation or attempt}

\author{
Augusta Rodrigues de Oliveira Zana* \\ Universidade Federal do Rio de Janeiro- UFRJ, Rio de Janeiro, Rio de Janeiro, Brasil
}

\section{Maria J ulia Kovács**}

Universidade de São Paulo - USP, São Paulo, São Paulo, Brasil

\begin{abstract}
RESUMO
O atendimento a pacientes com ideação ou tentativa de suicídio provoca grande mobilização no profissional de saúde. No diálogo entre a prática clínica e as proposições do Código de Ética Profissional, surgem dilemas éticos e questionamentos sobre como agir. Este trabalho teve por objetivo compreender como Psicólogos lidam com esses pacientes na prática clínica, bem como investigar as questões éticas envolvidas. A proposta metodológica foi qualitativa. Foram realizadas entrevistas com três Psicólogos clínicos que aceitaram participar do estudo e que atendiam ou já tinham atendido paciente(s) com ideação ou tentativa de suicídio. Foi possível observar como o suicídio mobiliza o Psicólogo tanto do ponto de vista pessoal quanto profissional. A questão da quebra do sigilo a partir do Código de Ética foi apontada como possibilidade. Todos os participantes da pesquisa trouxeram a preocupação com o vínculo terapêutico e o cuidado com o paciente, o que indica a complexidade do tema.
\end{abstract}

Palavras-chave: Suicídio, Psicólogo, Código de Ética.

\section{ABSTRACT}

The care of patients ideating or attempting suicide produces great mobilization on the part of health professionals. Considering clinical practice and the propositions of the Professional Code of Ethics, ethical dilemmas and questions on how to proceed arise. This article aims to verify how psychologists cope with these patients in their clinical care, as well as the ethical issues involved. A qualitative approach was employed. Interviews were conducted with three clinical psychologists, who accepted to participate on the study and were attending or had attended patient(s) ideating or attempting suicide. It was possible to observe how suicide mobilizes psychologists in their personal and professional point of view. The breach of secrecy considering the Psychology Code of Ethics was discussed as a possibility. All participants pointed out their concerns about the therapeutical bond and their patient's care, which stress the complexity of this issue.

Keywords: Suicide, Psychologist, Code of Ethics. 


\section{I ntrodução}

A vida de profissionais de saúde mental envolve intensa mobilização psíquica, pois o paciente os confronta com ansiedade e conflitos (PEREIRA, 2001). No caso de atendimento a pacientes com ideação ou tentativa de suicídio, essa mobilização leva o profissional a entrar em contato com seus questionamentos, angústias e dúvidas (SANTOS, 2007).

O problema do suicídio é complexo. Durkheim, em sua conhecida obra, O suicídio, já tratava da dificuldade de conceituar o suicídio, uma vez que "se se aceita a acepção vulgar, corre-se o risco de distinguir o que deve ser confundido ou de confundir o que deve ser distinguido" (DURKHEIM, 2005, p. 11). É preciso cuidado com tentativas de categorização (DUTRA, 2000), pois agrupar pessoas que buscam o suicídio em categorias esbarra no fato de que "as razões do suicídio serão tão variadas como o próprio número de pessoas que buscam essa alternativa" (ANGERAMI-CAMON, 1999, p. 57).

Para Binswanger (1958) não se deve ligar de forma imediata o suicídio a um acontecimento em especial, é preciso compreender de que maneira possíveis motivos tornaram-se efetivos, já que cada pessoa experiencia e atribui sentido a fatos de seu ambiente de maneira particular. Muitas vezes, os desencadeantes do ato suicida são tomados como causas, quando, na verdade, tal ato é o resultado de uma complexa rede de fatores, parte deles inconscientes (CASSORLA, 1991). Kovács (1992) afirma que:

\footnotetext{
O suicídio é um ato muito complexo, portanto não pode ser considerado em todos os casos como psicose, ou como decorrente de desordem social. Também não pode ser ligado de forma simplista a um determinado acontecimento como rompimento amoroso, ou perda de emprego. Trata-se de um processo, que pode ter tido o seu início na infância, embora os motivos alegados sejam tão somente os fatores desencadeantes. (KOVÁCS, 1992, p. 173)
}

Kovács (op cit) destaca que, para alguns autores, o suicídio só pode ser assim considerado se o indivíduo estiver consciente e lúcido no momento de seu ato. A intencionalidade do ato autodestrutivo é característica distintiva do suicídio, embora não seja fácil avaliá-la, pois envolve a possibilidade ou não de reversão do método utilizado e de providências que tornem possível a ação de terceiros.

Observa-se um grau de intencionalidade crescente à medida que se passa da ideação suicida para desejos, ameaças, tentativas, até o ato consumado. Para procurar compreender se a pessoa deseja viver ou morrer deve-se levar em conta a intencionalidade e letalidade do ato (Kovács, op cit). No entanto, estudos apontam que é falsa a idéia de que pessoas que falam em suicídio não chegam ao ato final. Ao 
contrário, a maioria das pessoas que cometeram suicídio apresentou ameaças verbais ou comportamentos autodestrutivos em algum momento (SANTOS, op cit).

Cassorla (op cit) indica que há ambivalência entre o desejo de viver e de morrer. O resultado desse conflito depende da força de cada um dos componentes, das circunstâncias que envolvem $o$ ato e da possibilidade de socorro. Muitas pessoas que tentam ou cometem suicídio não desejam a morte, e sim uma nova vida, em que sejam amadas. Observa-se no suicídio o pedido de ajuda, um grito de socorro.

Bastos (2009) conceitua o suicídio como um acontecimento subscrito por uma tendência à autodestruição e inserido em um contínuo existencial, caracterizado por diferentes graus de destrutividade. Os primeiros graus de autodestrutividade referem-se a fantasias inconscientes, presentes em todos nós, e que não significam que seu portador apresentará uma tentativa de suicídio. O segundo grau se caracteriza por alguma atitude que põe em risco a própria vida, isto é, ocorre uma tentativa de suicídio. No terceiro grau de autodestrutividade a pessoa apresenta um forte e firme desejo de se matar. Por isso, o autor afirma que:

[...] não existe o suicídio, mas suicídios, ou seja, considerando que há fantasias inconscientes de suicídios, há atitudes ambivalentes entre a vida e a morte e existem suicídios de fato [...] a autodestruição pode ser compreendida por um contínuo que se apresenta por diferentes graus. (BASTOS, 2009, p. 87)

O que perpassa cada um desses patamares é a questão vincular, por isso Bastos (op cit) propõe pensar o suicídio como um acontecimento complexo que ocorre principalmente entre a vida pessoal e a coletiva. A partir de Bleger, discute a autodestruição como um processo psicossocial, através da análise de seus patamares básicos: individual, das inter-relações (que têm seu início nas relações familiares), da instituição, e da sociedade como um todo.

O autor discute a questão dos vínculos, a partir do processo de socialização na família e de socialização secundária (grupos importantes pelos quais passamos no desenvolvimento). Baseando-se em Bleger, afirma que há dois tipos básicos de família: as de vinculação funcional, em que os membros tendem a se diferenciar, e as de vinculação disfuncional, com pendor para relações desestruturadas e cujos membros tendem a mostrar dificuldades de diferenciação. Esta dificuldade poderá ter papel relevante em certas tentativas e até em alguns suicídios fatais. No entanto, Bastos (op cit) destaca que a questão vincular não tem a pretensão de dar conta do objeto total da questão do suicídio, pois é preciso levar em conta a singularidade em cada caso. 
Para discutir a questão da singularidade, o autor apresenta a perspectiva junguiana, que defende a metáfora do estudo da alma, em oposição aos estudos exógenos sobre o suicídio, que o reduzem apenas ao lado "de fora" do indivíduo, explicando fenômenos humanos por "médias" e "desvios". A perspectiva junguiana considera o lado de "dentro", da alma, que desvela o significado do ato suicida:

\begin{abstract}
[...] a metáfora básica da alma, acima de tudo, fala da busca do significado que existe na singularidade de cada ato humano e, especialmente, no do suicídio. Quando se diz que não se trata de sermos a favor do suicídio, mas sim de compreender o que isso significa para a alma, estamos enxergando que há diferenças entre o suicídio visto de uma forma literal e de uma que se desvele o seu significado pela compreensão da psique. (BASTOS, 2009, p. 77)
\end{abstract}

Assim, existe a psicologia da pessoa que comete suicídio que o estuda e o percebe pelo "lado de fora" e a psicologia que o vê como uma problemática pelo "lado de dentro". Enquanto a primeira, em geral, tende a não considerar o significado do ato, na segunda a ênfase recai justamente sobre seu sentido e singularidade (BASTOS, op cit).

\title{
20 impacto do suicídio na equipe de saúde
}

Cassorla (op cit) indica que, nos pronto-socorros, é comum chegarem pacientes com tentativa de suicídio e risco mínimo de morte, devido à baixa letalidade do método utilizado. Frequentemente, a reação da equipe de saúde é de desprezo, pois o ato suicida é agressivo em relação à pessoa que o comete, mas também às pessoas próximas. Os profissionais de saúde também captam essa agressividade, e sentem como ataque a eles, porque se identificam com os objetos originalmente atacados. Como esses profissionais foram treinados para salvar vidas, quando se defrontam com esses pacientes, que não desejam viver, sentem sua vocação questionada.

Mesmo com todo o cuidado dispensado, alguns pacientes cometem suicídio enquanto estão sob cuidados médicos, causando grande impacto nos outros pacientes, familiares e equipe assistencial, provocando sentimentos de culpa, raiva e ansiedade (BERTOLOTE, MELLO-SANTOS, BOTEGA, 2010).

Botega, Reginato, Silva, Cais, Rapeli, Mauro, Cecconi e Stefanello (2005) realizaram pesquisa com enfermeiras no hospital geral da Universidade Estadual de Campinas, buscando compreender suas atitudes em relação ao suicídio por meio da aplicação do Suicide Behavior Attitude Questionnaire (SBAQ). Os resultados indicaram que apenas $17 \%$ dos profissionais se consideram preparados para lidar 
com pacientes sob risco de suicídio, $36 \%$ se sentem capazes de perceber quando um paciente está sob risco de suicídio e $12 \%$ concordaram com o direito que a pessoa tem de cometer suicídio. Entre os que discordam, $85 \%$ consideram que a vida é presente de Deus, não cabe ao ser humano encerrá-la.

Santos (op. cit) realizou pesquisa com o objetivo de investigar como Psicólogos percebem as dificuldades e necessidades no atendimento e acompanhamento a pacientes com ideação suicida. O trabalho de Santos (op cit) foi realizado por meio de cinco entrevistas, sendo que todas as entrevistadas foram mulheres. A partir de entrevistas, observou que o desejo de morte do paciente provoca sentimentos de impotência no profissional. As entrevistadas mostraram que lidar com o desejo de morte dos pacientes é também considerar a própria finitude, e a psicoterapia pode ajudar neste processo.

No que se refere aos pacientes com ideação ou tentativa de suicídio, as entrevistadas afirmaram que estes vivenciam intenso sofrimento e falta de sentido em suas vidas, e que a tentativa de suicídio aparece como mensagem endereçada a alguém, como pedido de ajuda. Ao trabalhar com esses pacientes, procuram a vida no discurso da morte. Todas destacaram a necessidade de respaldo psiquiátrico, por considerarem que não é possível prever se o suicídio será efetivado ou não. Em geral, os pacientes estão passando por momentos de sofrimento e fragilidade, e, na maioria dos casos, necessitam de tratamento medicamentoso.

As entrevistadas destacaram também a importância do contrato terapêutico transparente, pois é a partir dele que se estabelece bom vínculo e se reforça a confiança do paciente em relação ao profissional. Se a vida está em risco, a pessoa indicada pelo paciente será contatada, e isso deve ser previamente combinado.

Assim, com base em sua pesquisa, Santos (op cit) indica que o atendimento a pessoas que tentam ou cometem suicídio leva o profissional de saúde a entrar em contato com seus próprios questionamentos, angústias e dúvidas, e a confrontar-se com seus limites.

A pesquisa realizada por nós inspirou-se na pesquisa de Santos acima referida, investigando os sentidos do suicídio e da prática clínica de Psicólogos. Consideramos também os aspectos éticos envolvidos no atendimento a pacientes com ideação ou tentativa de suicídio.

\section{O Psicólogo diante da ideação ou tentativa de suicídio: o que fazer?}

A questão dos cuidados psicológicos é fundamental quando se trata da questão do suicídio. Referindo-se ao segundo grau de destrutividade, Bastos (op cit) afirma que as tentativas de suicídio 
não devem ser supervalorizadas nem desvalorizadas, sendo necessário entendê-las e acolhê-las verdadeiramente. No que tange ao terceiro grau de autodestrutividade, como há grande probabilidade do suicídio se concretizar, é recomendável o trabalho de uma equipe multiprofissional (Médico, Psicólogo, terapeuta de família) e do grupo familiar.

O atendimento psicológico a pacientes com ideação ou tentativa de suicídio levanta questionamentos em relação a aspectos éticos, notadamente no que se refere à questão do sigilo. O exercício profissional do Psicólogo deve se pautar na ética para garantir relação adequada entre profissional, cliente e sociedade, de acordo com valores relevantes. Pode ser difícil para o Psicólogo deliberar e decidir, pois ações humanas ocorrem numa confluência complexa de circunstâncias: experimentos podem ferir a dignidade humana, um Psicólogo Clínico pode interferir muito na vida do paciente e o trabalho em instituições pode envolver conflito de interesses (LEOPOLDO E SILVA, 1998).

A ética envolve percepção de conflitos, autonomia de escolha e coerência (COHEN E SEGRE, 1994). Há diferença entre ética e moral, que Chauí (2000, p. 436) define como:

\begin{abstract}
Toda cultura e cada sociedade institui uma moral, ou seja, valores concernentes ao bem e ao mal, ao permitido e ao proibido, e à conduta correta, válidos para todos os seus membros. [...] No entanto, a simples existência da moral não significa a presença explícita de uma ética, entendida como filosofia moral, isto é, uma reflexão que discuta, problematize e interprete o significado dos valores morais.
\end{abstract}

Para Cohen e Segre (op cit), a ética profissional é importante para fornecer orientação ao profissional, resulta da integração entre eticidade (aptidão do indivíduo de exercer a função ética) e ética social, produzida na interação entre indivíduo e realidade social. $O$ exercício profissional do Psicólogo deve ser balizado por responsabilidade, cuidado e respeito, e está sujeito a julgamento ético para garantir a justa medida na relação entre profissional, cliente e sociedade.

O Código de Ética Profissional do Psicólogo (CONSELHO FEDERAL DE PSICOLOGIA, 2005) estabelece que o Psicólogo deve pautar sua conduta com base em princípios fundamentais, que versam sobre respeito, liberdade, dignidade, igualdade e integridade do ser humano. Este deve contribuir para eliminação da negligência, discriminação, exploração, violência, crueldade e opressão, atuar com responsabilidade social, analisando crítica e historicamente a realidade, e buscar contínuo aprimoramento profissional. Também indica que o Psicólogo deve contribuir para a universalização do acesso da população às informações, ao conhecimento da ciência 
psicológica, aos serviços e aos padrões éticos profissionais. Por fim, deve zelar para que o exercício profissional seja efetuado com dignidade e levar em conta as relações de poder nos contextos em que atua, bem como os impactos destas sobre suas atividades profissionais.

No Código de Ética, os artigos 6으, 9o e 10으 apontam que o sigilo profissional tem por finalidade proteger a pessoa atendida, e, no caso do Psicólogo, significa manter sob proteção as informações e fatos conhecidos por meio da relação profissional. Todo Psicólogo, em seu exercício profissional, está obrigado ao sigilo, sendo este um dos pontos fundamentais sobre os quais se assenta 0 trabalho profissional. Se houver necessidade de informar a respeito do atendimento a quem de direito, devem ser oferecidas apenas as informações necessárias para a tomada de decisão que afete 0 usuário (CONSELHO REGIONAL DE PSICOLOGIA DE SÃO PAULO, 2006).

Em casos excepcionais, é considerada a possibilidade de decisão do Psicólogo pela quebra do sigilo, pautado pela análise crítica e criteriosa da situação, tendo em vista os princípios fundamentais da ética profissional, buscando o menor prejuízo. É preciso analisar a situação à luz do próprio Código de Ética considerado como um todo, por envolver um conjunto de fatores a serem verificados: motivo da quebra de sigilo, circunstâncias em que pode ocorrer e modo de proceder do profissional.

Diante das orientações do Código de Ética, percebe-se que restam muitas dúvidas sobre como agir. Por exemplo, no que se refere a prestar apenas as informações necessárias no caso de quebra de sigilo, como dosar quais informações podem ser compartilhadas? Há diferentes posturas em relação a questões, tais como: o Psicólogo deve ou não tentar impedir que um paciente cometa suicídio, em caso positivo de que maneira e em que situações? Deve avisar os familiares, considerando que a quebra de sigilo pode interferir na relação entre terapeuta e cliente, afetando o sentimento de confiança?

Fukumitsu (2005) considera que, quando há potencial de suicídio, é importante não deixar o paciente sozinho, este precisa ser acompanhado no dia-a-dia. O trabalho de acompanhantes terapêuticos ou internação em instituições especializadas pode ser necessário. É importante ampliar o sistema de apoio, procurando ajudar a família na compreensão de que a pessoa que tenta ou comete suicídio pode não desejar a morte, e sim viver de outra maneira. É fundamental trabalhar em conjunto com psiquiatras, numa abordagem multidisciplinar.

A autora defende que as condutas acima referidas sejam tomadas quando há potencial de suicídio. Entretanto, é complicado circunscrever o que configura o "potencial de suicídio". O terapeuta 
pode não perceber indícios de que o paciente tem potencial suicida e ser pego de surpresa por uma tentativa de suicídio. Por isso é importante o contrato terapêutico, que pode resguardar o paciente e o Psicólogo. Esse contrato prevê a necessidade de avisar e proteger a pessoa, e baseia-se na confiança e na relação entre terapeuta e cliente.

\begin{abstract}
O terapeuta deve estar atento aos sinais sutis, senão ele pode ser acusado de negligência ou má prática. Também, para evitar acusações, é importante documentar todas as sessões, contatos telefônicos, sessões extras com o cliente, além de incluir no contrato terapêutico que o sigilo será quebrado em casos de risco de vida do cliente ou de outra pessoa, sempre lembrando que o terapeuta ligará para a família somente nesses casos e com o consentimento do cliente. (FUKUMITSU, op cit, p. 32)
\end{abstract}

Dessa maneira, a autora introduz a questão do sigilo, afirmando que este é mantido desde que não haja risco à vida. Quando se considera haver risco para suicídio, o Psicólogo pode, com consentimento do cliente, informar a família. Porém, é importante destacar que a quebra do sigilo nestes casos é um direito, não um dever.

Santos (op cit) afirma que o paciente que tenta suicídio precisa de alguém para confiar, por isso o vínculo com o terapeuta é importante. A atuação do profissional deve ser cercada de cuidados, tranqüilidade e segurança. O tratamento de forma franca, clara e honesta facilita a comunicação sem interferências, promovendo o estabelecimento da confiança, de modo que, em momentos de crise o paciente se sinta à vontade para entrar em contato com seus sentimentos e conflitos.

$\mathrm{Na}$ relação psicoterápica o sigilo é essencial, porque possibilita ao paciente falar de sua intimidade na certeza de que será respeitado e protegido no que se refere à manutenção do que é confidencial. Há casos em que o sigilo precisa ser rompido, como é o caso do suicídio, daí a importância de contratos terapêuticos claros.

Heck (1997) problematiza essa questão, discutindo a posição ética do profissional de saúde, de modo a refletir se a pessoa que tenta suicídio tem direito de tirar sua própria vida ou deve ser impedida pela equipe de saúde, que tem como princípio ético a promoção da vida, considerada como valor absoluto.

Profissionais de saúde têm como objetivo maior salvar vidas, mas é preciso considerar os direitos do paciente, e nessa tensão coloca-se o problema: os profissionais de saúde podem ou devem tentar impedir que o sujeito cometa suicídio?

Um dos princípios da bioética afirma que o indivíduo tem autonomia em suas ações e decisões, e o profissional de saúde não pode ignorar este fato. Na maioria das vezes, a pessoa que tenta suicídio está em sofrimento muito intenso e a questão é como diminuí-lo. 
Heck (op cit) aponta que a posição do clínico sobre a atitude da pessoa que tenta ou comete suicídio, está ligada a muitos questionamentos, há mais incertezas do que certezas. Considera inapropriado pautar-se apenas em questões abstratas e legais, defendendo que se compreenda e que não se condene a pessoa que tenta ou comete suicídio.

Acrescentamos a seguir as proposições de Hillman (1993) sobre o analista e o profissional de saúde. Para o autor, numa perspectiva junguiana, a análise não tem por objetivo promover adaptação social ou julgamentos. Aponta a importância de o Psicólogo manter a objetividade, entendida não no sentido de separação entre sujeito e objeto, como preconiza o método baseado nas ciências naturais, e sim de abertura ao outro, sem dirigi-lo orientado por suas próprias crenças e valores éticos, já que analista e sujeito poderão ter pontos de vistas diferentes.

No entanto, quando o suicídio é o problema em questão, como o analista pode ter uma atitude objetiva? Para Hillman (op cit, p. 25 e 26), "Objetividade significa abertura; e abertura a respeito do suicídio não é uma coisa facilmente conquistada", pois significa "um movimento em direção à morte, de uma maneira franca e sem medo".

A investigação analítica tem como objetivo compreender a intenção ou o ato suicida e não perdoar, condenar ou emitir julgamentos. Para se proteger a vida e prevenir o suicídio, há várias práticas para "normalizar" o sofredor, mas assim se negligencia a experiência singular. Por isso, Hillman (op cit, p. 32) afirma que, embora pareça contrário ao senso comum e à prática médica, "caso se defenda a vida psicológica, como deve fazer o analista, pode ser que se tenha que frustrar a vida física".

Medeiros (2002, p. 32), abordando o trabalho do Psicólogo nas instituições de saúde, indica que há muitas situações que constituem dilemas éticos na relação do Psicólogo com paciente, familiares e equipe de trabalho, e questiona:

\footnotetext{
Até onde manter o sigilo profissional? É possível quebrar o sigilo? Em quais situações? (...) Quais as informações sobre o paciente que devem constar no prontuário? Deve-se quebrar o sigilo em casos de violência física, abuso sexual ou negligência contra menores?
}

A autora questiona, então, em que o Psicólogo (que trabalha em instituições de saúde) deve se basear para que sua postura seja ética. Uma possibilidade é pautar-se no Código de Ética Profissional do Psicólogo, mas Medeiros (op cit) considera que convém questionar se a conduta ética pode se basear unicamente no cumprimento deste Código. Este se insere no quadro das normas jurídicas, é um sistema 
de regras, externo ao sujeito, cuja finalidade é regular as ações dos profissionais da categoria, por meio da indicação de responsabilidades, deveres e direitos.

O Código não oferece respostas às questões éticas, daí a necessidade de não se limitar aos conteúdos nele inscritos. Tem caráter referencial, serve como norteador para atividades dos profissionais da categoria, inscrevendo direitos, deveres e responsabilidades. As particularidades de cada situação exigem ampla reflexão que inclui o Código de Ética Profissional do Psicólogo, mas não se restringe a ele.

Outra possibilidade seria agir com base em convicções pessoais, guiados por valores e princípios individuais. Medeiros (op cit) indica que estes devem ser considerados e respeitados, mas, na relação com a pessoa atendida, não cabe priorizar aquilo que o profissional pessoalmente acredita e valoriza. Baseando-se apenas em suas crenças e valores pessoais, o Psicólogo pode induzir a adaptação da pessoa a padrões que podem não ser relevantes para o paciente.

Leopoldo e Silva (1998) enfatiza a importância da Bioética, que surgiu a partir da pressão de fatos históricos, reveladores de práticas de pesquisa em que estavam ausentes quaisquer parâmetros de consideração da dignidade do ser humano, como as práticas experimentais em seres humanos, conduzidas sob o nazismo por médicos e cientistas, na Segunda Guerra Mundial.

Um dos preceitos fundamentais da ética kantiana afirma que nenhum ser humano será visto como meio para a obtenção de qualquer finalidade, porque a dignidade humana impõe que o homem seja considerado somente como fim. Há direitos humanos, que se situam acima de qualquer outro interesse, e é nesta direção que podemos entender as preocupações éticas que se expressam nos códigos de conduta e em outros conjuntos de normas aplicadas às pesquisas e às profissões (Leopoldo e Silva, op cit).

Marcolino e Cohen (2008) apontam que os princípios da bioética são: autonomia, beneficência, não-maleficência e justiça. O princípio da autonomia se refere ao direito de que as pessoas se autogovernem, possam fazer suas escolhas. Requer que seja respeitada a vontade do paciente ou de seu representante nos valores morais e crenças, reconhecendo o domínio do paciente sobre a própria vida e intimidade. O princípio da beneficência requer que sejam atendidos os interesses importantes e legítimos dos indivíduos e que, na medida do possível, sejam evitados danos, visando o bem-estar e interesses do paciente. Já o princípio da não-maleficência está fundamentado na proposição de primeiro e acima de tudo não causar dano, não fazer o mal ou injustiça. O princípio da justiça exige eqüidade na distribuição de bens e benefícios na área de saúde.

No entanto, há situações em que se discute quais os limites da autonomia do paciente, que critérios definem a beneficência dos atos e o que se pode considerar como justo no que se refere à distribuição 
dos cuidados à saúde. O desenvolvimento de uma atitude ética envolve percepção de conflitos, liberdade e coerência. $O$ respeito à autonomia do paciente pode confrontar o profissional de saúde com seus valores. É no contato diário com o paciente que o médico questiona a conduta que pode ser considerada correta ou incorreta em determinada situação.

Na aplicação dos princípios da bioética à prática clínica é fundamental incluir a dimensão emocional da relação do profissional de saúde com o paciente, instituição e o que se considera justo nos modelos de assistência à saúde. Os profissionais precisam estar familiarizados com a bioética, para integrar os conceitos e ética às responsabilidades clínicas, numa prática interpessoal e intrapessoal envolvendo aspectos do relacionamento do profissional com seu paciente.

Este trabalho tem por objetivo buscar compreender como Psicólogos lidam com pacientes com ideação e/ou tentativa de suicídio na prática clínica, bem como possíveis dilemas éticos, enfatizando o diálogo entre a prática clínica e as proposições do Código de Ética Profissional.

\section{Método}

Esta pesquisa utiliza abordagem qualitativa. Foram convidados três Psicólogos, que aceitaram participar do estudo. Os critérios de inclusão dos participantes da pesquisa foram: ser Psicólogo clínico, atender ou já ter atendido paciente(s) com ideação ou tentativa de suicídio e ter aceito participar deste estudo. Não houve critério de exclusão à priori.

Foram realizadas entrevistas abertas com perguntas disparadoras que apresentamos a seguir:

1) O que significa suicídio para você, como pessoa e como profissional?

2) Percebe diferenças em relação ao sentido do suicídio para diferentes pacientes (que atende ou já atendeu)?

3) Na clínica, como lida com o paciente com ideação suicida?

4) Já viveu algum conflito ético relativo à questão do suicídio? No que se refere a esse tema, como vê a interlocução entre o que propõe 0 Código de Ética Profissional do Psicólogo e sua prática clínica?

Antes do início de cada entrevista foi apresentado o Termo de Consentimento Livre e Esclarecido, que, após a leitura, foi assinado. As entrevistas foram realizadas em local de escolha dos participantes, buscando-se conforto e privacidade.

No que tange às considerações éticas, foram garantidos: sigilo, confidencialidade e privacidade do participante, para que não 
houvesse possibilidade de identificação. Os nomes que constam do artigo são fictícios.

Buscou-se, numa abordagem qualitativa, compreender os sentidos dados pelos participantes, sem pretensão de generalização. 0 enfoque fenomenológico foi utilizado para captar a experiência vivida com mais precisão. Segundo Forghieri (2002), o sentido que uma situação tem para a pessoa é uma experiência íntima que não se reduz ao que é diretamente observável. Nossa reflexão sobre os relatos dos participantes centrou-se nos elementos que permitissem compreender o sentido do suicídio, na prática do Psicólogo, preservando-se a singularidade.

\section{Apresentação dos resultados}

Os três participantes entrevistados abordaram diferentes aspectos sobre o tema em questão, e suas falas convergem em determinados aspectos e divergem em outros. A história de vida e as experiências vividas estão relacionadas com os sentidos atribuídos ao suicídio, presentes em sua prática clínica. Apresentamos a seguir uma sinopse dos relatos.

\section{Patrícia}

Uma vez eu ouvi de um paciente, que foi esse que tentou o suicídio durante o processo, que ele falou assim, "às vezes eu me sinto como uma pipa e eu sinto que você é a linha"

No início da entrevista, quando questionada sobre o sentido do suicídio, Patrícia trouxe o tema da relação entre suicídio e culpa. Ela vivenciou pessoalmente o suicídio de um familiar quando era criança, situação que causou grande impacto para ela e seus familiares. Este acontecimento suscitou questões sobre atribuição de culpa nos casos de suicídio, pois, ao contrário de seus familiares, Patrícia acreditava não haver culpados:

[...] na época, houve toda uma movimentação de descobrir quem era o culpado sabe, e eu sempre achando assim, mas foi ele, ninguém matou ele, não tem um culpado..."

Dessa situação, o que ficou para Patrícia foi "um ponto de interrogação", para o qual conseguiu encontrar algumas respostas no âmbito profissional. A partir de sua prática clínica, passou a considerar que o suicídio não é opção ou impulso, e sim um processo no qual o último ato elimina o sofrimento, já que a pessoa não vê outra saída. 
Eu vejo o suicídio assim, ninguém opta pelo suicídio [...] Eu acho que é um processo, é um processo de dor, de muita dor, e muitas vezes a pessoa não vê saída...

Em relação ao sentido do suicídio, Patrícia considera que, na maioria dos casos, trata-se de uma tentativa de mudar uma situação para a qual não se percebe outra saída.

[...] a maioria das vezes... eu vejo que é a vontade de mudar a situação. Então eu não vejo assim um desejo de morte, mas assim "eu não agüento mais essa situação, preciso sair dessa situação, e não estou vendo outra maneira de sair dessa situação que não seja acabando com tudo".

A entrevistada também abordou a questão do suicídio como forma de "chamar a atenção", apontando que o cuidado deve ser o mesmo porque, mesmo se a pessoa não deseja realmente morrer, uma tentativa de suicídio pode levar a morte por um erro de cálculo.

[...] aquela pessoa que tenta o suicídio... para chamar atenção ou aquela que tenta de fato, para mim não tem diferença clinicamente falando, porque ela pode errar a mão, e se ela errar a mão ela vai cometer. Então tem que ser olhado, tem que ser cuidado.

No que se refere ao manejo clínico, Patrícia afirmou que é necessário cuidado quando se lida com paciente com ideação ou tentativa de suicídio. O Psicólogo oferece apoio e sustentação para um vínculo, que por ser frágil, pode se romper facilmente. É importante buscar conhecer a história de vida do paciente, compreender e acolher, sem julgamentos.

Eu acho que precisa tomar um cuidado, afinal de contas é um paciente que está em risco [...] tem que perceber muito o caminho que ele está fazendo, o percurso que ele está fazendo, porque está tênue, é tênue a linha. Uma vez eu ouvi de um paciente, que foi esse que tentou o suicídio durante o processo, que ele falou assim, "às vezes eu me sinto como uma pipa e eu sinto que você é a linha".

Ao considerar as questões éticas, Patrícia afirmou que não atende casos de suicídio sem o acompanhamento de um psiquiatra e, em caso de risco de vida, avisa familiares, sem quebrar o sigilo sobre o que é dito na sessão, tendo combinado previamente com o paciente.

O Código, ele deixa muito claro que se o paciente se coloca em risco de vida, você pode quebrar [o sigilo]. Mas assim, essa quebra... Quando vem um paciente geralmente com ideação suicida muito grave, ele sempre vem acompanhado. [...] E esse alguém acaba sendo o interlocutor, assim, a pessoa com quem a gente acaba entrando em contato. Então 
a quebra do sigilo... você não precisa quebrar o sigilo, você só precisa dar um sinal. [...] Então assim, o que foi dito, o que foi estruturado, eu não costumo dizer, eu não costumo quebrar.

Nossas impressões em relação à entrevista de Patrícia se referem ao fato de ter vivenciado o suicídio de um familiar. Esse fato parece influenciar sua maneira particular de compreender o suicídio e, consequentemente, sua relação com o paciente. A vivência do suicídio de pessoa próxima a ela suscitou questões, que a acompanham na sua prática clinica.

\section{Michele}

Não tenho nenhuma coisa pronta assim "opa deixa eu tirar isso aqui da gaveta que agora o problema é esse" [...] é como eu falei, tentar entender o significado disso para ele

Michele iniciou a entrevista trazendo o suicídio como "uma gota d'água". O sentido do suicídio está ligado a um processo em que surgem ideações suicidas, situações difíceis que vão se acumulando, e uma mistura de sentimentos e dificuldades. Dependendo de como a pessoa lida com sentimentos, problemas, situações de vida, estresse, preocupações e perdas surge ideação suicida e a possível concretização do suicídio.

[...] eu acho que a pessoa até chegar ao suicídio é porque ela chegou às ideações, ela foi acumulando, foi acumulando situações, foi acumulando os sentimentos, as dificuldades dela, e para mim o suicídio é uma gota d'água, a tentativa de suicídio é uma gota d'água, dentro de um balde cheio.

No caso de pacientes com comportamento autodestrutivos, Michele considera que é perigoso quando um membro do grupo concretiza o suicídio. Contou de uma paciente que perdeu uma pessoa muito próxima, que também tinha comportamentos autodestrutivos. Como o comportamento da paciente é muito parecido, "a pulga fica atrás da orelha". Essa paciente não trazia ideações, mas se via completamente perdida porque tinha perdido a referência de como ser pessoa.

[...] essas pessoas têm outras junto com elas que também são parecidas, têm comportamentos [autodestrutivos] parecidos, e aí é perigoso quando uma delas consegue concretizar [...] é uma confusão de sentimentos.

No que se refere ao manejo clínico, Michele não tem uma forma padronizada. Trabalha com o que é trazido pelo paciente, busca compreender o sentido do suicídio para ele e não emite julgamentos 
sobre o que é certo ou errado. O número de sessões também é definido caso a caso.

[...] eu trabalho muito com o que o paciente traz no momento, então eu tento entender por quê, qual o significado disso para ele, o que está fazendo com que ele ache que isso seja uma possibilidade para ele [...] Então é ali na hora assim, não tenho nenhuma coisa pronta assim "opa deixa eu tirar isso aqui da gaveta que agora o problema é esse".

Quando considera o momento como crítico, Michele indica que o paciente procure um psiquiatra, já a grande oscilação de emoções impossibilita o trabalho terapêutico, uma vez que o paciente não consegue refletir.

[...] a emoção fica sobe e desce, sobe e desce [...] eu acho importante o trabalho de um psiquiatra nesse momento, para poder estar medicando, ajudando a controlar um pouco essas emoções, para que ele [...] consiga refletir [...] Porque eu sentar com uma pessoa que está nesse turbilhão, eu não vou conseguir fazer nada [...] e posso prejudicar mais ainda o paciente.

Michele abordou também a importância de um contrato terapêutico claro. Ela combina previamente com o paciente que, caso coloque sua vida em risco, entrará em contato com pessoa indicada por ele.

Então de início eu já tenho com o paciente um contrato, às vezes verbal, às vezes por escrito, de que ela já me deixa de antemão 2 telefones, duas pessoas que eu possa entrar em contato caso eu achar que a vida dela está em risco. [...] eu não estou proibindo ela de decidir o que ela quer fazer da vida dela. Mas se, num momento de risco, eu estou junto ali, ou de necessidade de alguém, eu vou entrar em contato.

No que se refere ao sigilo, Michele afirmou que apenas fala sobre o paciente em supervisão e com 0 profissional que faz 0 acompanhamento conjunto, geralmente o psiquiatra. No caso de contato com pessoa indicada pelo paciente, em caso de risco de vida, não são revelados conteúdos das sessões.

Não é porque eu vou ligar para alguém que eu vou contar todo o caso dela. É ligar para o telefone que ela me passou e falar "olha, eu acho que está num momento crítico, precisa de um acompanhamento mais presente, então é importante você estar junto, levá-la no psiquiatra para ver o que está acontecendo". É até aí, não vou passar conteúdos do que está sendo trabalhado dentro da sessão. 
No final da entrevista, Michele relatou que quando chegou o primeiro caso de suicídio, não queria atender. Ao refletir sobre isso, concluiu que seu medo se devia à crença de que devia salvar a vida do paciente e pôde então perceber que não era disso que se tratava na clínica, pois cabe ao Psicólogo compreender a situação sem colocar seus juízos morais. Mas Michele expressa o quanto é difícil ver o paciente fazendo escolhas que ela não faria, e que ainda hoje sente medo. Fica evidente o envolvimento do Psicólogo, a impossibilidade de não se afetar, como pessoa ou profissional.

[...] eu fiquei arranjando mil desculpas [para não receber o paciente], aí eu parei e falei "espera um pouco, qual é o meu medo?", o medo na verdade é da pessoa tentar suicídio ali comigo, é de eu ter que salvar a vida dele, mas eu não tenho que fazer nada disso. Eu tenho que entender junto com ele que escolha é essa, e que é uma escolha dele, que eu não tenho que pôr a minha questão moral em cima disso. [...] É duro? É muito duro, você de repente ver uma pessoa tendo escolhas que você acha absurdas e que você nunca faria isso na sua vida. Mas é escolha dela, e aí é isso que você tem que trabalhar [...] Às vezes eu ainda tenho medo, tenho, porque não é fácil trabalhar com esses pacientes.

\title{
Paulo
}

\begin{abstract}
Mas a experiência de ficar entre a cruz e a espada é muito corriqueira, muito... Quem você ouve ali, o que você preserva... A perspectiva da pessoa, o direito do sigilo dela, a vida dela, a continuidade do processo. Quando aparece esse fenômeno na clínica é muito difícil de pensar... O que está em jogo?
\end{abstract}

Paulo inicia a entrevista trazendo o sentido do suicídio como desesperança ou esperança. Relatou que para ele, pessoalmente, suicídio significa desesperança, pois imagina que o que poderia leválo a pensar nisso seria a perda de toda a esperança na vida e nos outros. Na clínica, Paulo observa esse sentido, mas também percebe que, muitas vezes, o suicídio tem o sentido de um apelo esperançoso, na busca de ser visto e amado pelo outro.

Acho que o suicídio para algumas pessoas tem a esperança de captura do outro, de ser visto, de se sentir ligado ao outro [...] Tem pessoas que tem esse uso da tentativa de suicídio para chamar o outro, aí é hiper esperançoso, é uma questão radical de buscar o contato.

Paulo exemplificou essa situação recorrendo a uma paciente, com várias internações psiquiátricas e atentados contra si, cujas tentativas de suicídio tinham o sentido de testar se o pai e marido iriam salvá-la, para que se assegurasse de sua importância para eles. 
Essa paciente tinha um irmão mais velho com deficiência, e a vivência da paciente era que sua mãe teria se dedicado apenas a ele, trazendo uma imagem de si mesma chorando no berço sem que ninguém aparecesse.

[...] o enredo é esse, é ela verificar se o marido dela e o pai vão salvá-la, se ela é importante a ponto de alguém segurála e estar vendo o que ela está fazendo, é sempre um teste se o outro está com ela, porque ela não tem essa certeza, ela não tem essa garantia de que ela está acompanhada, de que ela é importante para o outro.

A partir desse relato, Paulo discute a questão dos vínculos. Considera que essa paciente vivenciou uma experiência de desligamento radical, por isso tem a necessidade de testar os vínculos. Porém, considera que existe também uma questão social, já que nossa sociedade oferece poucas oportunidades de vinculação, ao contrário de épocas passadas, em que casar-se e ter filhos era praticamente certo, o que trazia garantias.

Acho que o mundo de hoje oferece muito pouca, pouca chance para as pessoas terem essa sensação de estarem ligadas umas às outras. [...] as relações não são mais garantidas como antigamente. Uma pessoa na década de 30 sabia que ia casar, sabia que ia ter filhos, então a ligação estava garantida, por mais arbitrária que ela fosse.

Acredita que não há método para lidar com pacientes com ideação suicida, cada encontro é único. Em sua prática clínica, a maneira como ele lida com o paciente depende do sentido do suicídio, que é singular, e da maneira pela qual ele é afetado pelo que o paciente lhe conta.

[...] não sei se tem um método para identificar o que é certo, o que cabe, o que não cabe, é a experiência afetiva do momento, como nós somos tomados, para mim é isso, como eu sou tomado na hora.

A maneira como é "tomado" pelo relato do paciente é importante na decisão de recorrer ou não a familiares e psiquiatra. Alguns pacientes têm a questão do suicídio e precisam poder falar sobre isso, por isso é importante não se precipitar no que se refere a entrar em contato com terceiros. Paulo considera que uma situação diferente ocorre no caso de pacientes que nunca haviam trazido o suicídio como questão, e, de repente, essa idéia aparece, irrompe como um ato. Nesses casos, Paulo considera a possibilidade de recorrer a outro tipo de proteção, e se ampara na sua experiência emocional com o paciente para tomar tal decisão. 
[...] tem paciente que eu liguei para o médico, liguei para o pai, para a mãe, mas eu não sei se tem uma medida técnica para isso [...] Tem a ver com a minha experiência emocional [...] tem pacientes que não têm essa questão, e o suicídio surge, irrompe como um ato mesmo. Não tinha nada sobre isso, e de repente surge a idéia de um suicídio, que a pessoa está alterada, está esquisita, e que me desespera. Isso acho que eu tomo como uma medida para poder procurar outro tipo de proteção. Por outro lado, tem pacientes que precisam falar de suicídio, acho que a análise deve ser capaz de abrigar isso, alguém que traz o suicídio como tema, como questão da vida.

Paulo relaciona essa questão à vinculação, pois considera que o risco de vida é maior quando o paciente exclui o outro. Há pacientes que trazem a questão do suicídio incluindo o Psicólogo no enredo, convocando-o. Ao contrário, quando o suicídio irrompe como ato Paulo vê a marca de um desligamento, e por isso considera mais grave.

\begin{abstract}
Quando começa a aparecer um ato, ligado ao suicídio, que tem um desligamento, um isolamento, acho que é mais grave. A pessoa está sozinha, não comunica, começa a ficar sozinha, você tem notícias por outras pessoas que a pessoa está tentando se matar ou que... Enfim, acho que quando tem um desligamento, quando não tem um uso do outro é muito mais grave. Enquanto tem fala... tem fala, então você tem uma direção desse gesto, desse ato, tem esperança.
\end{abstract}

No que se refere às questões éticas, Paulo afirmou que seus dilemas não são exatamente em relação ao Código de Ética, mas à ética clínica, de como considera e se posiciona diante do sofrimento do outro. Contou de um paciente dependente químico que abusou de cocaína e telefonou para ele de madrugada. O paciente estava na rua sozinho, muito mal. Paulo decidiu avisar a família e o médico, dizendo que ele estava na rua e precisava de ajuda. Na entrevista, Paulo se questionou sobre os aspectos éticos envolvidos nesse caso.

Não sei se em termos formais da ética eu, eu...rompi algum tipo de... mas... acho que no fundo o apelo desse cara era ajuda, "eu preciso de mais ajuda"... E um limite onde eu estava completamente impotente ali, e super preocupado com o cara, o cara estava morrendo na rua...

No final da entrevista, Paulo se referiu às suas falas como "provisórias", e que constantemente revê seus pontos de vista, com base em cada experiência singular. Falou também da dificuldade de o Psicólogo lidar com tais questões. 
Mas a experiência de ficar entre a cruz e a espada é muito corriqueira, muito... Quem você ouve ali, o que você preserva... A perspectiva da pessoa, o direito do sigilo dela; a vida dela; a continuidade do processo. Quando aparece esse fenômeno na clínica é muito difícil de pensar... O que está em jogo?

Paulo parece ter aproveitado o espaço da entrevista para refletir, já que em vários momentos trazia questões, ponderava sobre elas considerando aspectos diferentes, e essas reflexões que aparecem na entrevista pautam sua prática clínica.

\section{Discussão}

Trouxemos uma sinopse das três entrevistas realizadas, da maneira como os discursos foram trazidos pelos participantes da pesquisa. Iniciaremos em seguida uma reflexão sobre essas entrevistas, procurando traçar pontos de aproximação e distanciamento entre as falas dos entrevistados, relacionando com os autores apresentados na introdução teórica deste artigo.

\subsection{Sentidos do suicídio}

Nas entrevistas apareceram diferentes sentidos para o suicídio, sendo que alguns se repetem nas entrevistas dos profissionais, que, embora com termos diferentes, fazem referências a processos semelhantes.

Nas falas de Patrícia e Michele, o suicídio aparece como último ato num processo doloroso para o qual a pessoa não vê mais saída, "uma gota d'água, dentro de um balde cheio". Michele afirmou que há pessoas que vivenciam experiências de desamparo muito intensas quando se defrontam com situações disruptivas, porque têm dificuldades de lidar com perdas. De maneira parecida, Patrícia afirmou que o sentido do suicídio pode estar relacionado à vivência de uma situação insuportável, para a qual a pessoa não vê outra saída a não ser o suicídio. Podemos também traçar um paralelo com o que foi trazido por Paulo, ao falar do sentimento de desesperança e desligamento da vida.

Em situações de sofrimento, o suicídio também pode ter o sentido de "um apelo esperançoso" (Paulo), esperança de ser visto pelo outro, buscando contato e amor. Nesses casos, o Psicólogo pode ser levado a pensar que o objetivo é chamar a atenção (Patrícia), mas é importante lembrar que, por um erro de cálculo, uma tentativa de suicídio pode levar à morte, mesmo quando esta não era a intenção principal.

O suicídio com sentido de "chamar a atenção" ou de "apelo esperançoso" encontram paralelo no que Cassorla (1985 e 1991) 
afirma sobre a ambivalência entre o desejo de viver e de morrer. Cassorla (op cit) e Santos (2007) vêem no suicídio um pedido de ajuda, e o perigo de uma tentativa de suicídio "para chamar a atenção" está no fato de que pode levar à morte. Isso está de acordo com estudos, trazidos por esses dois autores, que apontam que é falsa a idéia de que pessoas que falam em suicídio não chegam ao ato final.

Considerando o sentido de apelo, o suicídio passa a ser um "teste de vínculos", como trazido por Paulo. É interessante notar que dois participantes traçaram relações entre suicídio e pobreza de vínculos sociais. Michele considera que uma pessoa sem vínculos está impossibilitada de compartilhar com outras, que poderiam ajudar a ver situações da vida de maneira diferente. Paulo acredita que a questão é mais ampla, relacionando-se à estruturação do mundo atual, que oferece poucas possibilidades de vinculação, com relações não garantidas, em contraste com épocas passadas. Essa questão que aparece no discurso dos entrevistados encontra paralelo na ênfase dada por Bastos (2009) à questão vincular, que o leva a pensar o suicídio como um acontecimento que ocorre entre a vida pessoal e a coletiva.

Os entrevistados também trouxeram outros sentidos do suicídio, dentre ao quais destacamos a perda de referência e o sentimento de estar vivo. Como descrito na sinopse da entrevista de Michele, uma paciente, que apresentava comportamentos autodestrutivos e perdeu uma amiga com atitude semelhante, passou a vivenciar forte perda de referência. No que se refere ao sentir-se vivo, Paulo relatou o caso de um paciente para quem a mutilação fazia com que se sentisse vivo, cortava-se e, ao ver o sangue escorrer, sentia alívio.

Ainda sobre os sentidos do suicídio, é importante destacar que nenhum dos participantes fez associação do suicídio com problemas psicopatológicos, e, de maneira semelhante à pesquisa de Santos (2007), todos relacionaram o suicídio com intenso sofrimento psíquico.

\subsection{Práticas clínica}

Todos os entrevistados acreditam que é importante acolher e compreender o paciente, sem julgamentos de valor, como aponta Hillman (1993), ao afirmar que a análise não tem por objetivo a adaptação social ou julgamento do ato suicida. Patrícia destacou que não se trata de procurar convencer o paciente a não cometer suicídio, e que é ilusão o Psicólogo acreditar ter esse poder. Paulo também não acredita que se deva argumentar com o paciente sobre 0 suicídio. Michele apontou que o Psicólogo não deve introduzir seus valores morais, e sim compreender os motivos junto com o paciente. 
No que se refere ao manejo, Michele enfatizou a importância de trabalhar com o que o paciente traz no momento e Patrícia destacou que busca conhecer sua história de vida. No discurso de todos os entrevistados apareceu a importância do vínculo de confiança entre terapeuta e paciente, para que um assunto como suicídio seja abordado, o que encontra paralelo na pesquisa de Santos (2007), que trata da importância da disponibilidade psíquica do terapeuta e do estabelecimento do vínculo.

Outro ponto de concordância entre todos os entrevistados é a singularidade de cada paciente, de maneira que generalizações não seriam apropriadas. Michele e Paulo destacaram que cada encontro é único e não há regras ou método para lidar com o paciente com ideação ou tentativa de suicídio.

Ao se referirem ao contrato terapêutico, os participantes apontaram a questão do acompanhamento psiquiátrico e comunicação com a família em caso de risco de vida, o que também é referido por Fukumitsu (2005) ao mencionar a importância da ampliação do sistema de apoio, envolvendo a família e o psiquiatra.

Patrícia afirmou que não cuida de pessoas com ideação ou tentativa de suicídio sem o acompanhamento de um psiquiatra, que ministre medicação. Michele destacou que, no caso de pacientes em estado crítico, indica a procura de um psiquiatra, porque a oscilação muito grande de emoções impossibilita a reflexão e o trabalho terapêutico, de maneira que a medicação assume importância para auxiliar no controle das emoções. Paulo não se refere à obrigatoriedade de acompanhamento psiquiátrico, embora tenha realizado atendimentos conjuntos por meio de contatos telefônicos com o profissional.

Patrícia e Michele consideram importante avisar os familiares, em caso de risco de vida, e, para não comprometer o vínculo terapêutico, combinam este procedimento previamente com o paciente. Patrícia propõe dois "combinados" no início do acompanhamento: 1) quando - cliente está pensando em cometer suicídio pode telefonar ao terapeuta em qualquer horário, e 2) se houver risco de vida, o terapeuta pode entrar em contato com o familiar e/ou o psiquiatra. Michele de início estabelece um contrato com o paciente, em que este disponibiliza o telefone de duas pessoas com quem ela possa entrar em contato, caso julgue que a vida do paciente corre risco.

Paulo não se refere à obrigatoriedade de comunicar alguém no caso de ideação suicida. Relatou que atendeu pacientes sem ter entrado em contato com ninguém, exemplificando com o caso de uma paciente, que trazia argumentos filosóficos para o suicídio como saída legítima, boa e racional. Considerou que a paciente realmente precisava falar sobre suicídio e que, se tivesse tomado a atitude de entrar em contato com familiares teria sido um equívoco. Sustentar sua posição permitiu que a paciente falasse sobre suicídio, e que alguém a escutasse, assim como propõe Hillman (1993). 


\subsection{Aspectos éticos}

Patrícia e Michele estabelecem um contrato terapêutico que prevê a possibilidade de entrar em contato com familiar e/ou psiquiatra se houver risco de vida. Ambas concordam que a quebra de sigilo se refere à possibilidade do suicídio, os outros conteúdos abordados em terapia não seriam mencionados.

Patrícia afirma que o Código de Ética do Psicólogo estabelece que, em caso de risco de vida, o Psicólogo pode quebrar o sigilo, o que não significa um dever, mas uma possibilidade. Michele indica que quando há necessidade de entrar em contato com familiar, em caso de risco de suicídio, não revela o que está sendo trabalhado na sessão. Indica que o paciente está vivenciando um momento crítico e precisa de acompanhamento mais presente da família.

De fato, como indica o Conselho Regional de Psicologia de São Paulo (2006), em casos excepcionais, é considerada a possibilidade de o Psicólogo decidir pela quebra do sigilo, pautado pela análise crítica e criteriosa da situação, tendo em vista os princípios fundamentais da ética profissional e a busca do menor prejuízo. Mesmo assim o consenso sobre esta decisão não é fácil.

Paulo não propõe a obrigatoriedade de avisar familiar ou psiquiatra, nem estabelece contrato prévio com o paciente no que se refere à quebra de sigilo. Toma providências se sentir que o risco de morte é real, como ocorreu no caso do paciente dependente químico, descrito na sinopse da entrevista de Paulo. Ele não tinha autorização prévia do paciente para tomar essa atitude, e por isso o paciente 0 questionou sobre ter agido sem seu consentimento. Paulo explicou que decidiu quebrar o sigilo devido à gravidade e ao fato de estar impotente diante da situação, em que o paciente estava na rua e poderia morrer.

Paulo também relatou casos em que havia participação da família e da equipe multiprofissional desde o início da terapia, e, nesses casos, mantinha uma interlocução. Assim, Paulo considera a possibilidade de acompanhamento psiquiátrico e de avisar pessoas próximas em caso de risco de vida, mas aponta esta intervenção como possibilidade e não como princípio geral. Além disso, considera que não é indicado se precipitar, pois há casos em que é importante para o paciente poder falar sobre o suicídio.

"O que me preocupa muito mais é com a possibilidade de matar um processo de alguém, sabe? De numa tentativa de proteção impedir com que o cuidado com a pessoa continue." (Paulo) 


\section{Considerações finais}

De maneira geral, há pontos de convergência na fala dos participantes de nossa pesquisa e Fukumitsu (2005), no que se refere à preocupação com o contrato terapêutico, ao informar à família quando há risco de suicídio. Um dos participantes considera que a postura ética está para além da observância estrita do Código de Ética Profissional do Psicólogo, como aponta Medeiros (2002).

Esta discussão é relevante, uma vez que, o Código de Ética Profissional do Psicólogo estabelece que, em casos excepcionais, o Psicólogo pode romper o sigilo, o que não significa que deve fazê-lo. Como indica Medeiros (2002), o Código serve como norte, mas as particularidades de cada situação exigem ampla reflexão. Chauí (2000) afirma que ética implica em reflexão, discussão, problematizando e interpretando o significado dos valores morais.

É importante questionar se posicionamentos em relação ao suicídio não estariam pautados pela máxima de "salvar a vida a qualquer custo", lógica de profissionais de saúde, que foram treinados para isso, como indica Cassorla (1985). Os questionamentos não se restringem ao suicídio, abarcando outros aspectos, como a finalidade do processo terapêutico. Como afirma Hillman (1993), na posição do analista é importante estar em sintonia com a necessidade do paciente falar sobre sua morte, numa posição contrária à lógica do "salvar a vida a qualquer custo": "caso se defenda a vida psicológica, como deve fazer o analista, pode ser que se tenha que frustrar a vida física" (op cit, p.32).

A questão que permanece é: tem o sujeito o direito ao suicídio, preservando sua liberdade e autonomia? E o profissional de saúde, como se posiciona?

A partir das entrevistas realizadas nesta pesquisa, pode-se observar como o suicídio mobiliza o Psicólogo, do ponto de vista pessoal e profissional. Dois participantes estabelecem contrato prévio com 0 paciente sobre informar familiares em caso de risco de vida. A questão da quebra do sigilo a partir do Código de Ética foi apontada como possibilidade, e não obrigatoriedade, e pode ser vista como prejuízo menor quando a vida está em risco.

Mas a "experiência de ficar entre a cruz e a espada", trazida por um dos participantes, parece sintetizar a posição do Psicólogo diante de questões tão complexas. Por um lado, há a preocupação com o bemestar e a vida do paciente e, por outro, o risco de tomar atitudes precipitadas, prejudicando a continuidade do processo terapêutico, já que este é baseado num vínculo de confiança, que pode ficar ameaçado diante da quebra de sigilo.

Diante da complexidade do problema, seria interessante que os Conselhos Regionais e o Conselho Federal de Psicologia 
congregassem Psicólogos para discutir as implicações éticas do manejo clínico de pacientes com ideação e/ou tentativa de suicídio.

\section{Referências}

ANGERAMI-CAMON, V. A. Solidão e suicídio. In: Solidão: a ausência do outro. São Paulo: Pioneira, p. 47-62, 1999

BASTOS, R. L. Suicídios, psicologia e vínculos: uma leitura psicossocial. Psicologia USP, São Paulo, v. 20, n. 1, janeiro/março, p. 67-92, 2009.

BERTOLOTE, J. M, MELLO-SANTOS, C. e BOTEGA, N. J. Detecção do risco de suicídio nos serviços de emergência psiquiátrica. Revista Brasileira de Psiquiatria, São Paulo, v. 32, supl II, p. S87-S95, outubro 2010.

BINSWANGER, L. The case of Ellen West. In MAY, R. Existence. New York, NY: Basic Books, p. 237-364, 1958.

BOTEGA, N. J., REGINATO, D. G., SILVA, S. V., CAIS, C. F. S., RAPELI, C. B., MAURO, M. L. F., CECCONI, J. P. e STEFANELLO, S. Nursing personnel attitudes towards suicide: the development of a measure scale. Revista Brasileira de Psiquiatria, São Paulo, v.27, n. 4, p. 315-318, 2005.

CASSORLA, R. M. S. O que é suicídio. São Paulo: Abril Cultural: Brasiliense, 1985.

CASSORLA, R. M. S. O impacto dos atos suicidas no médico e na equipe de saúde. In: ___. (coordenador). Do suicídio: estudos brasileiros. Campinas-SP: Papirus, p. 149-165, 1991.

CHAUÍ, M. Convite à filosofia. São Paulo: Ed. Ática, 2000.

COHEN, C. e SEGRE, M. Breve discurso sobre valores, moral, eticidade e ética. Bioética, Brasíia-DF, v. 2, n. 1, p. 19-24, 1994.

CONSELHO FEDERAL DE PSICOLOGIA. Código de ética profissional do Psicólogo. Brasília-DF, 2005.

CONSELHO REGIONAL DE PSICOLOGIA DE SÃO PAULO. Manual de orientações. São Paulo, 2006.

DURKHEI M, É. O suicídio. São Paulo: Martin Claret, 2005

DUTRA. E. M. S. Compreensão de tentativas de suicídio de jovens sob o enfoque da abordagem centrada na pessoa. Tese (Doutorado em Psicologia) - Instituto de Psicologia, Universidade de São Paulo, São Paulo, 2000, 195 p.

FORGHIERI, Y. C. Psicologia fenomenológica: fundamentos, métodos e pesquisa. São Paulo: Pioneira, 2002.

FUKUMITSU, K. O. Suicídio e psicoterapia: uma visão gestáltica. Campinas: Editora Livro Pleno, 2005.

HECK, R. M. O suicídio e a posição ética do profissional de saúde. Cogitare Enfermagem, Curitiba-PR, v. 2, n. 1, p. 86-89, janeirojunho 1997. 
HILLMAN, J. Suicídio e alma. Petrópolis, RJ: Vozes, 1993

KOVÁCS, M. J. Comportamentos autodestrutivos e o suicídio. In . (Org.). Morte e desenvolvimento humano. São Paulo: Casa do Psicólogo, p. 171-194, 1992.

LEOPOLODO E SILVA, F. Da Ética filosófica à ética em saúde. In COSTA, S. I. F., GARRAFA, V., e OSELKA, J. (coordenadores). I niciação à bioética. Brasília: Conselho Federal de Medicina, p. 1936, 1998.

MARCOLINO, J. A. M. (in memorian) e COHEN, C. Sobre a correlação entre a bioética e a psicologia médica. Revista da Associação Médica Brasileira, São Paulo, v. 54, n. 4, p. 363-368, 2008.

MARTINS, J. e BICUDO, M. A. V. A pesquisa qualitativa em psicologia: Fundamentos e recursos básicos. São Paulo: Editora Moraes, 1989.

MEDEIROS, G. A. Por uma ética na saúde: algumas reflexões sobre a ética e o ser ético na atuação do Psicólogo. Psicologia: Ciência e Profissão, Brasília-DF, v.22, n.1, p. 30-37, 2002.

Pereira, A. M. T. B. A saúde mental de profissionais de saúde mental: uma investigação da personalidade de Psicólogos. Maringá: Eduem, 2001.

SANTOS, A. B. B. A primeira hora: as dificuldades e desafios dos profissionais de psicologia em tratar e compreender pacientes com ideação ou tentativa de suicídio. Tese (Mestrado em Psicologia) Instituto de Psicologia, Universidade de São Paulo, São Paulo, 2007, $184 \mathrm{p}$.

\section{Endereço para correspondência}

Augusta Rodrigues de Oliveira Zana

R. Frei Caneca, 8 - Centro - Rio de Janeiro - RJ . CEP: 20.211-030

Endereço eletrônico: augusta_rodrigues@yahoo.com.br

Maria J ulia Kovács

Av. Prof. Mello Moraes, 1721 - CEP 05508-030 - Cidade Universitária - São Paulo SP.

Endereço eletrônico: mjkoarag@usp.br

Recebido em: 21/09/2011

Reformulado em: 18/01/2012

Aceito para publicação em: 16/02/2012

Acompanhamento do processo editorial: Alexandra Cleopatre Tsallis

\section{Notas}

* Psicóloga do Instituto Estadual de Hematologia Arthur de Siqueira Cavalcanti (HEMORIO). Mestre em Teoria Psicanalítica pelo Programa de Pós Graduação em Teoria Psicanalítica da Universidade Federal do Rio de Janeiro (UFRJ) e Psicóloga pelo Instituto de Psicologia da Universidade de São Paulo - IP-USP.

** Professora Doutora do Instituto de Psicologia da Universidade de São Paulo - IPUSP. Departamento de Psicologia da Aprendizagem, do Desenvolvimento e da Personalidade. 